\title{
Identification of Laser Weld Penetration Based on Fuzzy C-means algorithm
}

\author{
Jianbin Liang ${ }^{1, a}$, Xiangdong Gao ${ }^{1, b_{*}}$, Deyong You ${ }^{1, \mathrm{c}}$, Zhenshi $\mathrm{Li}^{2}$, \\ and Weiping Ruan ${ }^{2}$ \\ ${ }^{1}$ School of Electromechanical Engineering, Guangdong University of Technology,
}

\author{
No.100 West Waihuan Road, Higher Education Mega Center, Panyu District, Guangzhou 510006, \\ China \\ ${ }^{2}$ Guangdong Metalforming Machine Works Co.Ltd \\ No.1 Jindou Road, Daliang, Shunde, Foshan 528300, Guangdong, China \\ atankhero@126.com, bgaoxd666@126.com, 's.w.i.m@163.com, *Corresponding author
}

Keywords: high-power fiber laser welding, weld penetration, molten pool, FCM

\begin{abstract}
Weld penetration is an important standard of welding quality identification. This paper proposes a weld penetration status identification method based on the high-speed visual detection and fuzzy C-means algorithm (FCM). In a fiber laser butt-joint welding of Type 304 austenitic stainless steel plate with a high power $6 \mathrm{~kW}$ continuous wave fiber laser, an infrared sensitive high-speed video camera was used to capture the dynamic images of the molten pools. Molten pool characteristic parameters were extracted by image processing, and those parameters were used to identify the weld penetration status with FCM. Experimental results showed that the weld penetration status could be evaluated by the molten pool images during fiber laser welding.
\end{abstract}

\section{Introduction}

Weld penetration is an important standard of welding quality identification. Lack of penetration may create cracks easily and decrease weld seam strength and elongation. So weld penetration status identification has a great research value in automatic welding. However, it is difficult to measure the weld penetration directly due to actual welding environment restrictions. An important phenomenon during deep penetration laser welding is that a molten pool in the weldment will appear a keyhole. In a fiber laser butt-joint welding of Type 304 austenitic stainless steel plate with a high power $6 \mathrm{~kW}$ continuous wave fiber laser, an infrared sensitive high-speed video camera was used to capture the dynamic images of the molten pools. Then, molten pool characteristic parameters were extracted by image processing. By analyzing the change of the characteristic parameters during welding process, it was found that these parameters were related to the weld penetration status. FCM was used to build the relation model to detect the weld penetration status.

\section{Experimental setup}

The experimental system consisted of an IPG fiber laser welding equipment (laser power 6kW), shielding gas (argon), a Panasonic 6-axis robot and a welding experimental platform equipped with a high speed camera, motor servo and fixing devices. The schematic drawing of the whole experiment system is shown in Fig.1. To eliminate the interference and obtain near infrared images of a molten pool, a combination filtering system with a filter length of 960-990nm were placed in front of the vision sensor. Molten pool image recordings were carried out at 1000 frames/s by a $512 \times 512$ pixel high speed NAC camera. The used material was a stainless steel plates with dimensional size of $150 \times 100 \times 10 \mathrm{~mm}$, and the seam gap was $0.1 \mathrm{~mm}$. The welding speed was $2.5 \mathrm{~m} / \mathrm{min}$. The welding path was an oblique trajectory, which reflected the actual situation of welding seam offset in industries $[1,2]$. 


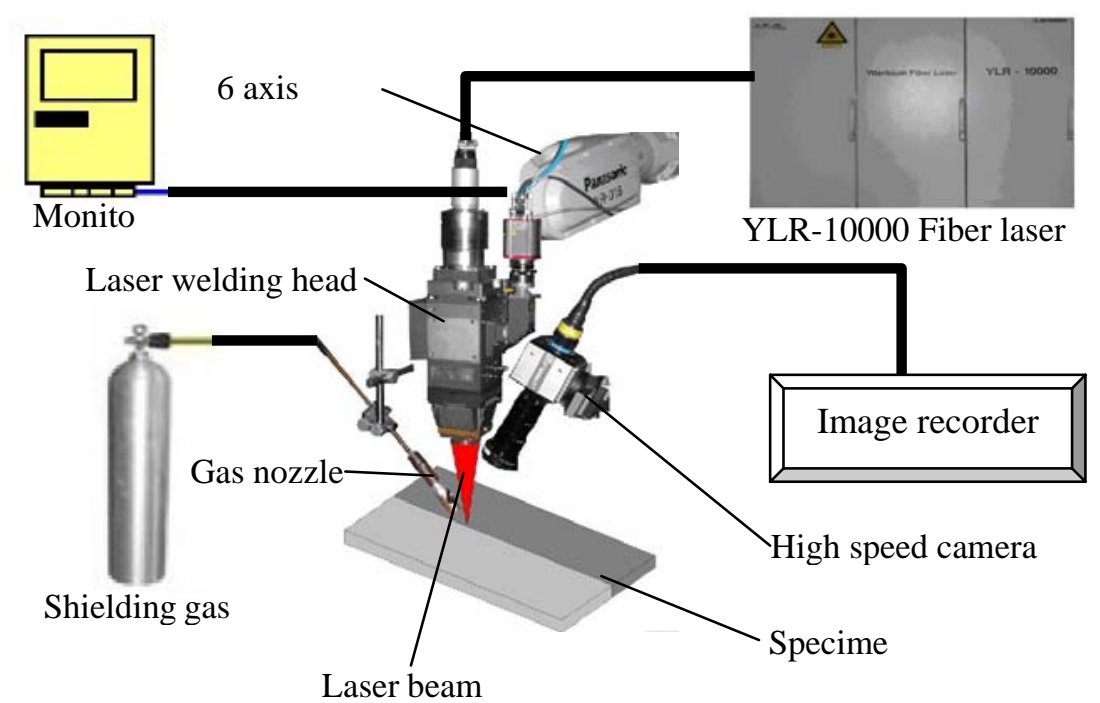

Fig.1 Schematic of fiber laser welding experimental setup

\section{Image preprocessing}

Fig. 2 shows an original and some processed images of molten pools. The original image of a molten pool (Fig.2a) was a gray image. Fixed threshold method was used to obtain the segmented image (Fig.2b) of keyhole area. It could be used to calculate the area of the keyhole. Then, the molten pool images were divided from the top of original images and median filtering was also used to eliminate the noise jamming (Fig.2c). The images were divided equally into left-right two parts (Fig.2d) and the divided images were used partially by Otsu threshold segmentation [3]. After threshold segmentation, two divided images were combined again and morphological open operation was used (Fig.2e). It could be used to calculate the width and average gray of molten pool images. Here, the original image was chosen randomly.

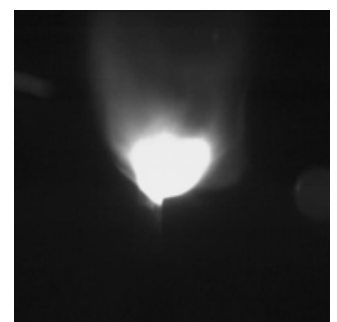

(a) Original image

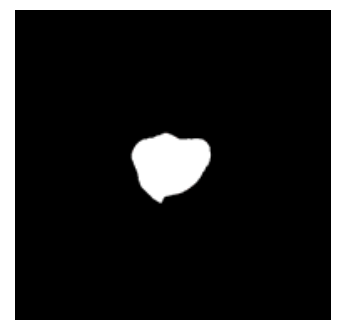

(b) Segmentation image

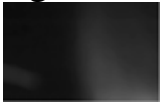

(d) Divided image

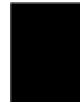

(e) Segmentation image

Fig.2 Keyhole images of high-power fiber laser welding

\section{Modeling of weld penetration status identification}

FCM is one of the most widely used clustering algorithms. It has many advantages such as simple, wide applications, fast, dealing with large and high-dimensional data effectively. In general, FCM has several steps as follow [4,5]: (1) Determining the number of clusters $c$, the fuzzifier $m$, stop threshold of iteration $\omega$ and initializing the cluster center matrix $V^{b}$ and the membership matrix $U^{b}$. (2) Calculating $V^{b}$ using Eq. 1. (3) Calculating $U^{b}$ using Eq. 2. (4) Calculating the Euclidean distance of $U^{b-1}$ and $U^{b}$. (5) Stopping iteration if the distance smaller than $\omega$, else going to Step 2. (6) Calculating clustering result matrix $Y$ using Eq. 3. 


$$
\begin{aligned}
& V^{b}=\left[v_{i}\right], v_{i}=\frac{\sum_{j=1}^{n}\left(\mu_{i j}\right)^{m} x_{j}}{\sum_{j=1}^{n}\left(\mu_{i j}\right)^{m}}, 1 \leq i \leq c \\
& U^{b}=\left[\mu_{i j}\right], \mu_{i j}=\left[\sum_{k=1}^{c}\left(\frac{\left\|x_{j}-v_{i}\right\|^{2}}{\left\|x_{j}-v_{k}\right\|^{2}}\right)^{\frac{1}{m-1}}\right]^{-1}, 1 \leq i \leq c, 1 \leq j \leq n \\
& Y=\left[y_{j}\right], y_{j}=k, \text { if } \mu_{k j}=\max \left\{\mu_{i j}, 1 \leq i \leq c\right\}, 1 \leq k \leq c, 1 \leq j \leq n
\end{aligned}
$$

where $b$ is the iteration times, $x_{j}$ is the feature data, $y_{j}$ is the result data and $k$ is the cluster number.

In order to observe the change of weld penetration status under different conditions, the moving path of laser beam was an oblique welding line. Fig. 3 shows the weld penetration status with image sequences in theory. Here, 1 stood for the penetration offset and 0 stood for the lack of penetration. Fig.5 shows the back of weldment. The welding penetration status could be easily identified by the back of weldment. Keyhole area (Fig.4), molten pool average gray (Fig.6) and molten pool width (Fig.7) were chosen as the characteristic parameters to build the weld penetration status identification model. Contrasting to Fig.3, Fig.6 and Fig.7, it showed that the molten pool average gray and width had similar change trends with the welding penetration status.

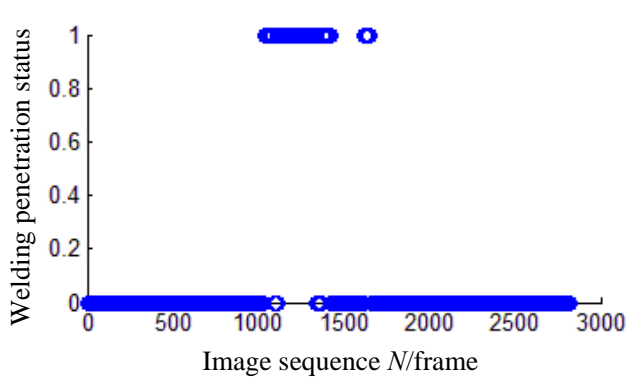

Fig.3 Weld penetration status in theory with image sequences

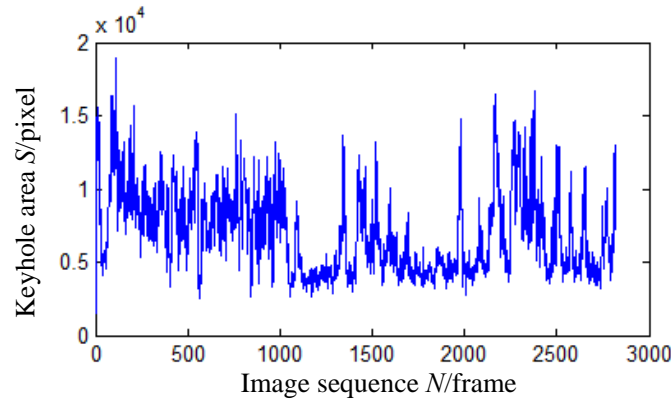

Fig.4 Measuring value of keyhole area with image sequences

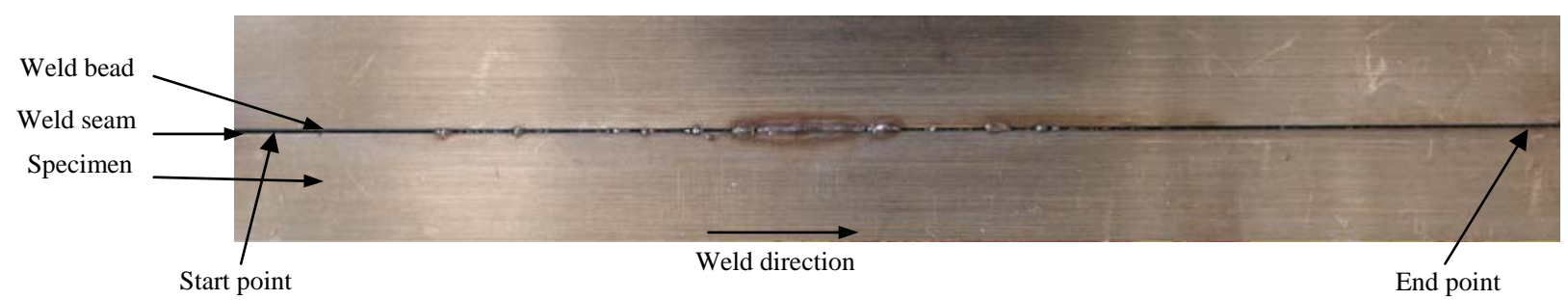

Fig.5 Back view of welded specimen

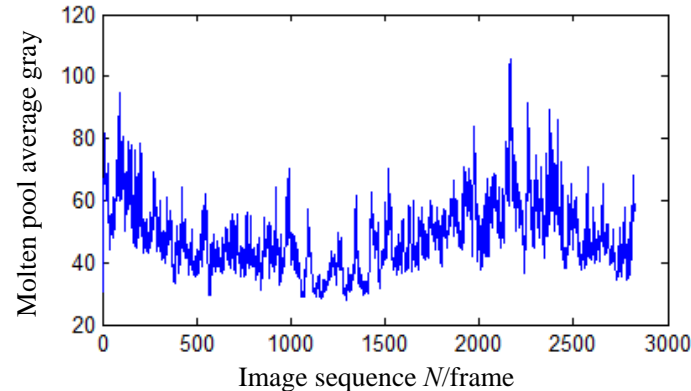

Fig.6 Measuring value of molten pool average gray with image sequences

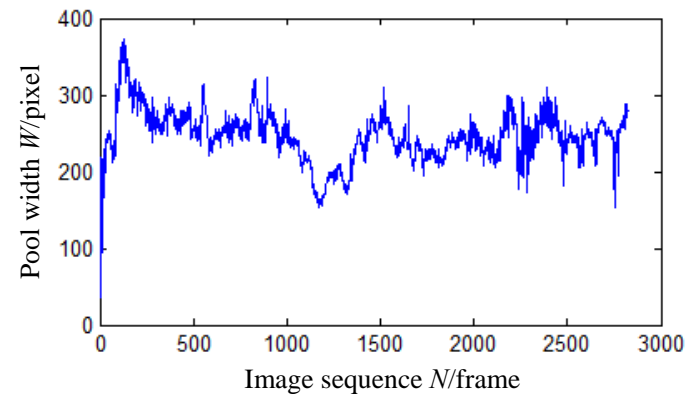

Fig.7 Measuring value of molten pool width with image sequences 
Table 1 shows the clustering results of FCM. The correct clustering percentage of penetration class had a high value and the lack of penetration class had a low value. It meant that FCM had a good performance in penetration class identification but was not satisfied in lack of penetration class where need to be improved in future. Parameter $m$ was changed from 1.2 to 3 , the correct percentage of penetration was decreasing and the lack of penetration was increasing. It showed that correct percentages could not all increase by changing parameter $m$.

Table 1 Results of clustering for laser weld penetration

\begin{tabular}{|c|c|c|c|c|c|c|c|c|c|c|}
\hline & 1 & 2 & 3 & 4 & 5 & 6 & 7 & 8 & 9 & 10 \\
\hline$m$ & 1.2 & 1.4 & 1.6 & 1.8 & 2 & 2.2 & 2.4 & 2.6 & 2.8 & 3 \\
\hline $\begin{array}{c}\text { Penetration correct } \\
\text { percentage [\%] }\end{array}$ & 96.7 & 96.7 & 96.4 & 96.4 & 96.4 & 96.2 & 96.2 & 95.6 & 95.6 & 95.6 \\
\hline $\begin{array}{c}\text { Lack of penetration } \\
\text { correct percentage [\%] }\end{array}$ & 40.3 & 40.8 & 41.9 & 42.8 & 43.6 & 44.5 & 45.4 & 45.9 & 46.3 & 46.7 \\
\hline
\end{tabular}

\section{Conclusions}

Using a high-speed imaging system to take the molten pool images in the process of high-power fiber laser welding can obtain the information of the change of the molten pool configuration and the weld penetration status.

Molten pool configuration is related to the weld penetration. The weld penetration can be evaluated by the molten pool images during high-power fiber laser welding. FCM had effect in weld penetration status identification. It had a good performance in fiber laser welding penetration class identification.

\section{Acknowledgements}

This work was supported in part by the National Natural Science Foundation of China (51175095), the Guangdong Provincial Natural Science Foundation of China (10251009001000001, 9151009001000020), the Specialized Research Fund for the Doctoral Program of Higher Education of China (20104420110001) and the Industrial and Information Fund of Shunde (SDLH201101). Many thanks are given to Katayama Laboratory of Osaka University, for their assistance of laser welding experiments.

\section{References}

[1] XiangDong Gao, DeYong You, S.Katayama and Y. Kawahito, in: Visual Techniques for Real-time Seam Tracking Monitoring during Fiber Laser Welding. Proceedings of LAMP2009-the 5th International Congress on Laser Advanced Materials Processing, Japan Laser Processing Society (JLPS), Cobe, JAPAN. 2009, (\#298) \#09-150.

[2] X.D.Gao, L.Mo, X.G.Zhong, D.Y.You and S.Katayama: Acta Physica Sinica. Vol.60 (2011), p.088105-1-8.

[3] Jianbin Liang, Xiangdong Gao, Deyong You, Zhenshi Li and Weiping Ruan: Advanced Materials Research, Vol.549(2012), p.1064-1068

[4] Haojun Suna , Shengrui Wanga and Qingshan Jiang: Pattern Recognition , Vol.37(2004), p.2027-2037

[5] Yunjie Zhang, Weina Wang, Xiaona Zhang, Yi Li: Information Sciences , Vol.178(2008), p.1205-1218 